\title{
The Successful Treatment of Pulmonary Pleomorphic Carcinoma with Pembrolizumab: A Case Report
}

\author{
Yoko Matsumoto $^{a} \quad$ Tamaki Miura $^{b}$ Hajime Horiuchi ${ }^{b}$ Kazuhiro Usui ${ }^{a}$ \\ ${ }^{a}$ Division of Respirology, NTT Medical Center Tokyo, Tokyo, Japan; ${ }^{b}$ Department of \\ Diagnostic Pathology, NTT Medical Center Tokyo, Tokyo, Japan
}

\section{Keywords}

Pulmonary pleomorphic carcinoma $\cdot$ Pembrolizumab $\cdot$ Programmed death ligand- $1 \cdot$ Immune checkpoint inhibitor $\cdot$ Non-small cell lung cancer

\begin{abstract}
Pulmonary pleomorphic carcinomas are rare malignant tumors, and no standard treatments have been established. We herein report the successful treatment of a patient with pulmonary pleomorphic carcinoma with pembrolizumab. A 51-year-old man who was a current smoker presented to our hospital due to dyspnea and hemosputum. Chest X-ray showed right-sided pneumothorax with pleural effusion; chest tube drainage was therefore performed. Computed tomography after chest tube drainage showed a cavitary nodule in the right upper lobe and right hilar and bilateral mediastinal lymphadenopathy. Surgery was performed for the diagnosis and treatment. He was eventually diagnosed with pulmonary pleomorphic carcinoma corresponding to clinical stage IVB (CT2aN2M1c [PLE, ADR, HEP]). The giant cells strongly expressed programmed death ligand- 1 , and the tumor proportion score was more than $50 \%$. Therefore, pembrolizumab was introduced as the first-line therapy. After 3 cycles of pembrolizumab, his right hilar and bilateral mediastinal lymphadenopathy and pleural dissemination notably decreased. Pembrolizumab might be an effective therapy for pulmonary pleomorphic carcinoma.




\section{Case Reports in Oncology}

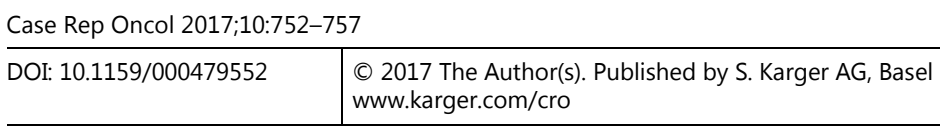

Matsumoto et al.: The Successful Treatment of Pulmonary Pleomorphic Carcinoma with Pembrolizumab: A Case Report

\section{Introduction}

Pulmonary pleomorphic carcinomas are rare and refractory to systemic chemotherapy, resulting in a poor prognosis [1-4]. No standard treatments or effective managements have been established.

We herein report the successful treatment of a patient with pulmonary pleomorphic carcinoma - in which programmed death ligand 1 (PD-L1) was strongly expressed - with pembrolizumab.

\section{Case Presentation}

A 51-year-old man who was a current smoker presented to our hospital due to dyspnea and hemosputum. He had a history of right-sided pneumothorax and pancreatitis. His chest $\mathrm{X}$-ray showed right-sided pneumothorax with pleural effusion; thus, chest tube drainage was performed (Fig. 1a, b). The cytology of the pleural fluid was benign. Computed tomography on the 3rd day revealed a cavitary nodule in the right upper lobe, and right hilar and bilateral mediastinal lymphadenopathy (Fig. 1c, d). An operation was performed on the 7th day for the diagnosis and treatment of pneumothorax. The tumor was found to have macroscopically invaded the visceral pleura and air leakage persisted. Wedge resection was performed, and he was discharged on the 3rd postoperative day.

A pathological analysis of the lung tumor revealed bizarre giant multinucleate cells containing abundant eosinophilic cytoplasm (Fig. 2a). Round cells with acinar and papillary patterns (components of adenocarcinoma) were also noted. Immunohistochemical studies showed that the giant cells were positive for cytokeratin AE1/AE3, and positive cells of p53 and Ki-67 were numerous. Vascular permeation was observed. The giant cells strongly expressed PD-L1 (Fig. 2b), and the tumor proportion score was more than 50\% (Dako 22C3 IHC platform). The patient was diagnosed with pulmonary pleomorphic carcinoma corresponding to clinical stage IVB (CT2aN2M1c [PLE, ADR, HEP]).

Pembrolizumab (200 mg/body) was introduced as the first-line therapy. The cytology of the pleural fluid at the initiation of therapy was malignant, and the pleural dissemination was found to have progressed in comparison to the initial medical examination (Fig. 1e). After 3 cycles of pembrolizumab, his right hilar and bilateral mediastinal lymphadenopathy and pleural dissemination notably decreased (Fig. 1f). He showed a partial response without any severe adverse events.

\section{Discussion}

Pulmonary pleomorphic carcinomas are rare and aggressive tumors; the reported incidence among all lung carcinomas has ranged from 0.1 to $0.4 \%[1,2]$. According to the 2015 World Health Organization (WHO) classification [5], pleomorphic carcinoma is defined as a poorly differentiated non-small cell lung carcinoma (NSCLC) in which spindle cell carcinoma and/or giant cell carcinoma form at least $10 \%$ of what would otherwise be a pure squamous cell carcinoma, adenocarcinoma or large cell carcinoma, or a carcinoma consisting only of spindle and giant cells. Pulmonary pleomorphic carcinoma has a more aggressive clinical course than other forms of NSCLC, and the response to chemotherapy is generally poor $[3,4$, 6]. 
Recently, immune checkpoint inhibitors have shown promising results in clinical trials, and are considered to be the standard treatment for advanced NSCLC [7-9]. Pembrolizumab, a humanized monoclonal antibody against PD-1 (programmed death 1), was approved as a first-line treatment for NSCLC in cases in which PD-L1 is strongly expressed [9]. The overexpression of PD-L1 in tumor membranes is one of the predictive biomarkers of anti-PD-1 antibodies.

It is reported that 70.5-90.2\% of pulmonary pleomorphic carcinomas show high levels of PD-L1 expression $[10,11]$, which is rather high in comparison to patients with other histological types of advanced NSCLC [7, 8]. Furthermore, the expression of PD-L1 in the giant cells of our patient was stronger than that in the adenocarcinoma cells, as was reported by Kim et al. [11]. The mechanism of mesenchymal differentiation in pulmonary sarcomatoid carcinoma is considered to be epithelial-mesenchymal transition [12], and the expression of PD-L1 is associated with the epithelial-mesenchymal transition in lung cancer [13, 14]. This mechanism may therefore explain the heterogeneous distribution of high PD-L1-expressing cells in this case.

\section{Conclusions}

To our knowledge, this is the first report to show the successful treatment of pulmonary pleomorphic carcinoma with pembrolizumab. Anti-PD-1 antibodies may be a promising therapeutic candidate for pulmonary pleomorphic carcinoma.

\section{Statement of Ethics}

The authors have no ethical conflicts to disclose.

\section{Disclosure Statement}

The authors declare that they have no conflicts of interest.

\section{References}

1 Fishback NF, Travis WD, Moran CA, Guinee DG Jr, McCarthy WF, Koss MN: Pleomorphic (spindle/giant cell) carcinoma of the lung. A clinicopathologic correlation of 78 cases. Cancer 1994;73:2936-2945.

-2 Chang YL, Lee YC, Shih JY, Wu CT: Pulmonary pleomorphic (spindle) cell carcinoma: peculiar clinicopathologic manifestations different from ordinary non-small cell carcinoma. Lung Cancer 2001;34:91-97.

3 Bae HM, Min HS, Lee SH, Kim DW, Chung DH, Lee JS, Kim YW, Heo DS: Palliative chemotherapy for pulmonary pleomorphic carcinoma. Lung Cancer 2007;58:112-115.

-4 Mochizuki T, Ishii G, Nagai K, Yoshida J, Nishimura M, Mizuno T, Yokose T, Suzuki K, Ochiai A Pleomorphic carcinoma of the lung: clinicopathologic characteristics of 70 cases. Am J Surg Pathol 2008;32:1727-1735.

5 Travis WD, Brambilla E, Nicholson AG, Yatabe Y, Austin JH, Beasley MB, Chirieac LR, Dacic S, Duhig E, Flieder DB, Geisinger K, Hirsch FR, Ishikawa Y, Kerr KM, Noguchi M, Pelosi G, Powell CA, Tsao MS, Wistuba I; WHO Panel: The 2015 World Health Organization Classification of Lung Tumors: Impact of Genetic, Clinical and Radiologic Advances since the 2004 Classification. J Thorac Oncol 2015;10:12431260. 
Matsumoto et al.: The Successful Treatment of Pulmonary Pleomorphic Carcinoma with Pembrolizumab: A Case Report

6 Ito K, Oizumi S, Fukumoto S, Harada M, Ishida T, Fujita Y, Harada T, Kojima T, Yokouchi H, Nishimura M; Hokkaido Lung Cancer Clinical Study Group: Clinical characteristics of pleomorphic carcinoma of the lung. Lung Cancer 2010;68:204-210.

7 Garon EB, Rizvi NA, Hui R, Leighl N, Balmanoukian AS, Eder JP, Patnaik A, Aggarwal C, Gubens M, Horn L, Carcereny E, Ahn MJ, Felip E, Lee JS, Hellmann MD, Hamid O, Goldman JW, Soria JC, Dolled-Filhart M, Rutledge RZ, Zhang J, Lunceford JK, Rangwala R, Lubiniecki GM, Roach C, Emancipator K, Gandhi L; KEYNOTE-001 Investigators: Pembrolizumab for the treatment of non-small-cell lung cancer. N Engl J Med 2015;372:2018-2028.

-8 Herbst RS, Baas P, Kim DW, Felip E, Pérez-Gracia JL, Han JY, Molina J, Kim JH, Arvis CD, Ahn MJ, Majem M, Fidler MJ, de Castro G Jr, Garrido M, Lubiniecki GM, Shentu Y, Im E, Dolled-Filhart M, Garon EB: Pembrolizumab versus docetaxel for previously treated, PD-L1-positive, advanced non-small-cell lung cancer (KEYNOTE-010): a randomised controlled trial. Lancet 2016;387:1540-1550.

-9 Reck M, Rodríguez-Abreu D, Robinson AG, Hui R, Csőszi T, Fülöp A, Gottfried M, Peled N, Tafreshi A, Cuffe S, O’Brien M, Rao S, Hotta K, Leiby MA, Lubiniecki GM, Shentu Y, Rangwala R, Brahmer JR; KEYNOTE-024 Investigators: Pembrolizumab versus chemotherapy for PD-L1-positive non-small-cell lung cancer. N Engl J Med 2016;375:1823-1833.

10 Chang YL, Yang CY, Lin MW, Wu CT, Yang PC: High co-expression of PD-L1 and HIF-1 $\alpha$ correlates with tumour necrosis in pulmonary pleomorphic carcinoma. Eur J Cancer 2016;60:125-135.

11 Kim S, Kim MY, Koh J, Go H, Lee DS, Jeon YK, Chung DH: Programmed death-1 ligand 1 and 2 are highly expressed in pleomorphic carcinomas of the lung: comparison of sarcomatous and carcinomatous areas. Eur J Cancer 2015;51:2698-2707.

12 Blaukovitsch M, Halbwedl I, Kothmaier H, Gogg-Kammerer M, Popper HH: Sarcomatoid carcinomas of the lung - are these histogenetically heterogeneous tumors? Virchows Arch 2006;449:455-461.

13 Kim S, Koh J, Kim MY, Kwon D, Go H, Kim YA, Jeon YK, Chung DH: PD-L1 expression is associated with epithelial-to-mesenchymal transition in adenocarcinoma of the lung. Hum Pathol 2016;58:7-14.

14 Shimoji M, Shimizu S, Sato K, Suda K, Kobayashi Y, Tomizawa K, Takemoto T, Mitsudomi T: Clinical and pathologic features of lung cancer expressing programmed cell death ligand 1 (PD-L1). Lung Cancer 2016;98:69-75. 


\section{Case Reports in Oncology}

\begin{tabular}{l|l}
\hline Case Rep Oncol 2017;10:752-757 \\
\hline DOI: 10.1159/000479552 & $\begin{array}{l}\text { C 2017 The Author(s). Published by S. Karger AG, Basel } \\
\text { www.karger.com/cro }\end{array}$ \\
\hline
\end{tabular}

Matsumoto et al.: The Successful Treatment of Pulmonary Pleomorphic Carcinoma with Pembrolizumab: A Case Report

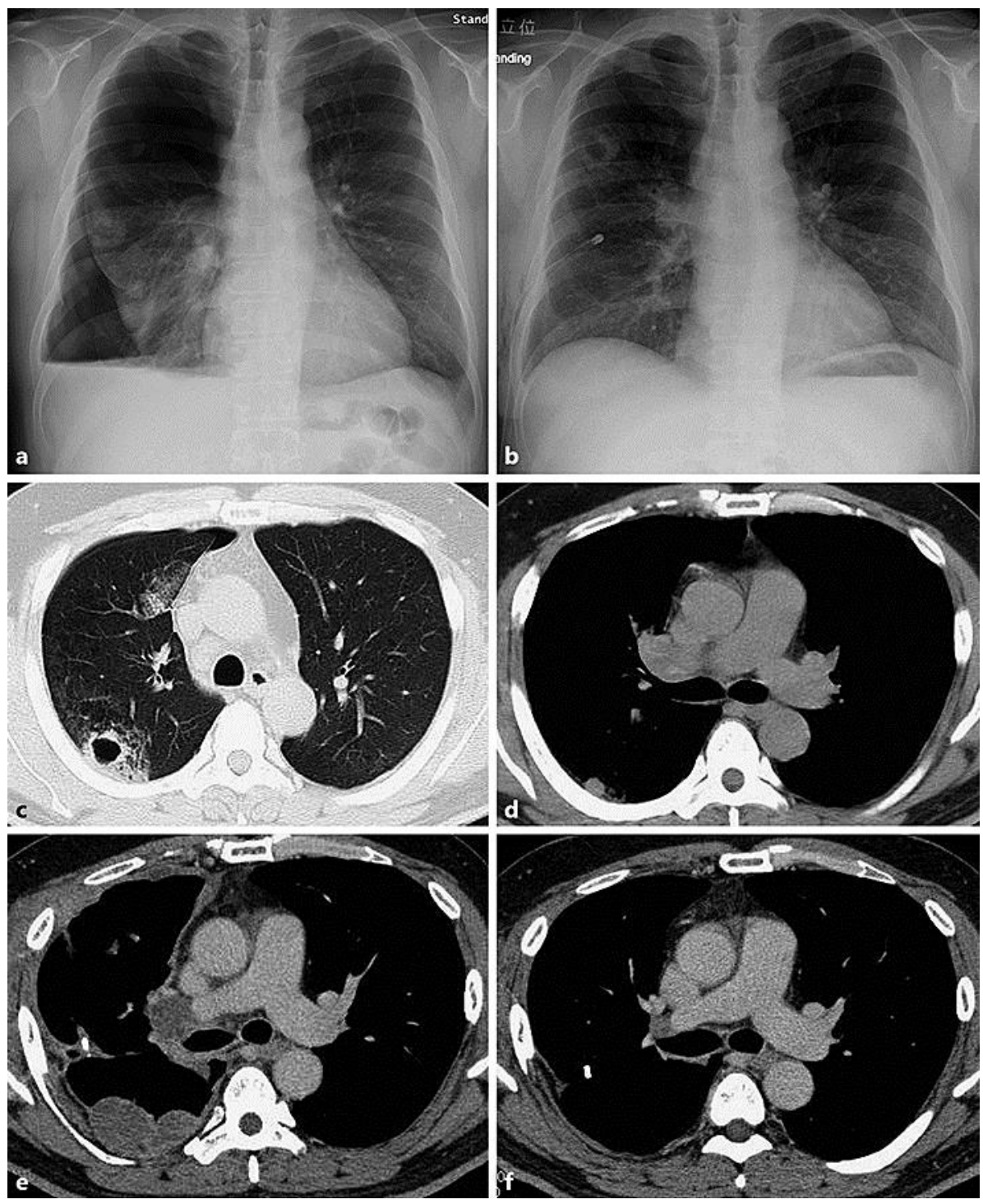

Fig. 1. Chest X-rays: on the initial medical examination (a) and after chest tube drainage (b). Computed tomography scans: before the operation (c, d), after the operation (e), and after 3 cycles of pembrolizumab (f). It was observed that the right hilar and bilateral mediastinal lymphadenopathy and pleural dissemination have decreased. 


\section{Case Reports in Oncology}

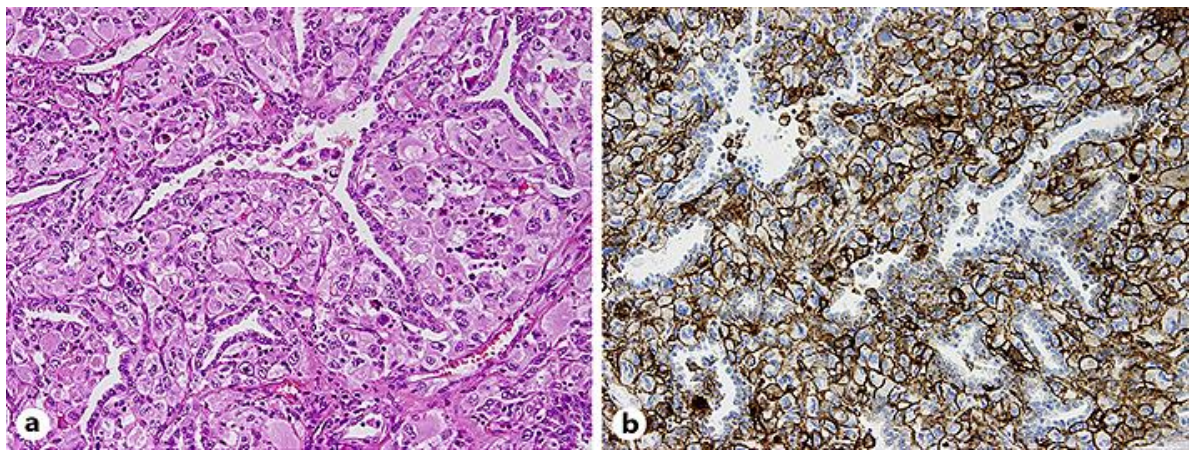

Fig. 2. The pathological analyses: hematoxylin and eosin staining (a) and PD-L1 staining (b).

Matsumoto et al.: The Successful Treatment of Pulmonary Pleomorphic Carcinoma with Pembrolizumab: A Case Report 